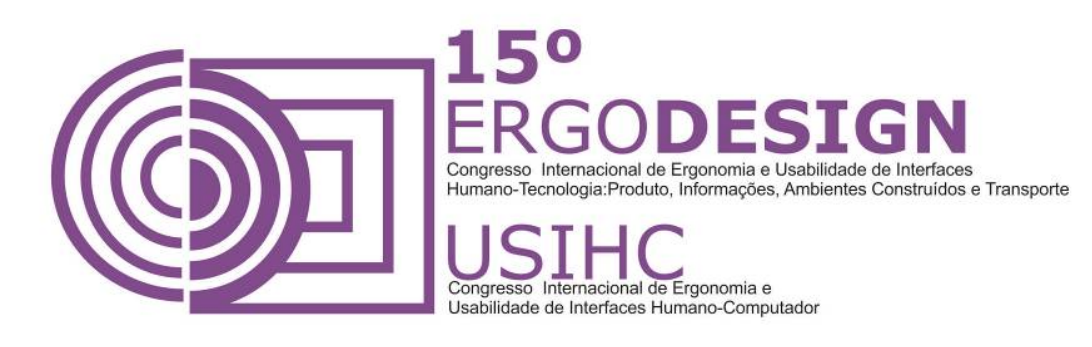

\title{
AVALIAÇÃO DAS CONDIÇÕES DE ACESSIBILIDADE EM UM ÓRGÃO PÚBLICO NA CIDADE DE TORRES, RS
}

\section{EVALUATION OF THE ACCESSIBILITY CONDITIONS IN A PUBLIC BUILDING IN THE CITY OF TORRES, RS}

\author{
JOCHIMS, Carolina Eloisa (1); \\ BINS ELY, Vera Helena Moro (2) \\ (1) UFSC, Mestranda \\ e-mail:jochims.carolina@gmail.com \\ (2) UFSC, Dr. Eng. \\ e-mail:vera@arq.ufsc.br
}

\begin{abstract}
RESUMO
O presente artigo analisa as condições de acessibilidade de um prédio público na cidade de Torres, RS, com objetivo de detectar os problemas encontrados por diversos tipos de usuários na utilização dos ambientes e dos serviços ofertados pelo órgão e propõe, ainda, soluções de acordo com as leis em vigor. Utilizando os métodos da revisão bibliográfica, do Walktrough (WHARTON et. al., 1994), do preenchimento das Planilhas do MP-SC e dos Passeios Acompanhados (DISCHINGER, 2000), é feita a análise dos problemas encontrados em relação à acessibilidade do local e são propostas as soluções necessárias ao cumprimento das normas em vigor.
\end{abstract}

Palavras-chave: Acessibilidade, Ergonomia, Prédios públicos.

\begin{abstract}
The presente article analyses the conditions of acessibility in a public building in the city of Torres, RS, in order to detect problems in environment that afect disable people in the activities offer in this building and point solutions according to the current laws. Using the methods of literature review, Walktrough (WHARTON et. Al.,1994), completing worksheets MP-SC and Guided Walks (DISCHINGER, 2000), is made an analysis of the problems encountered in relation to the accessibility of the site and proposes necessary solutions to meet the standards.
\end{abstract}

Keywords: Accessibility, Ergonomics, Public Buildings. 


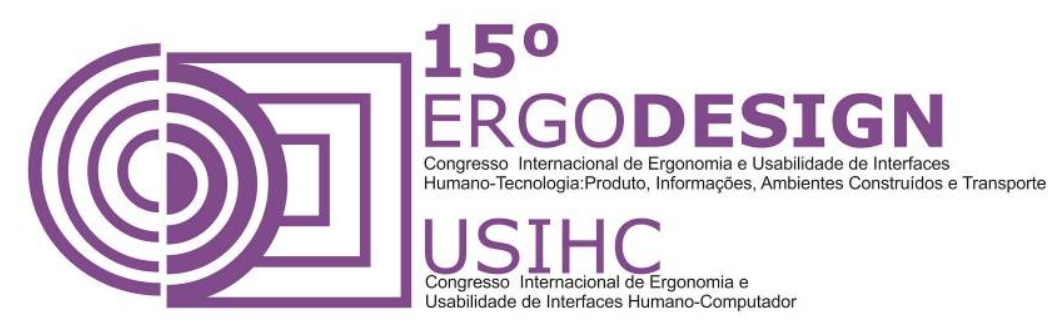

\section{INTRODUÇÃO}

O direito fundamental de ir e vir, garantido pela Constituição Brasileira de 1988, é, na prática, constantemente violado pela falta de condições de acessibilidade nos espaços públicos abertos e nas edificações. Tais condições roubam das pessoas com deficiência, além de seus direitos, sua dignidade, autoestima, possibilidades de vida plena e de exercício da cidadania. Apesar das leis existentes, grande parte das normas e recomendações não é respeitada, sendo necessários mecanismos de fiscalização, controle e mesmo de coação para que sejam cumpridas. Projetar, construir e adaptar edificações e espaços abertos para que sejam ou se tornem acessíveis A TODOS não é apenas uma questão de conscientização humanitária, mas antes uma obrigação dos poderes públicos, gestores e dos profissionais do planejamento, da organização dos espaços e da construção.

Os prédios públicos, de maneira especial, por sua característica de prestação de serviço à população, deveriam garantir a seus usuários, de forma plena, o acesso aos diversos serviços que lhes são devidos. A realidade, no entanto, é que esse acesso não ocorre. O presente artigo tem como objetivo a demonstração de um caso específico de necessidade de adaptação visando a acessibilidade, o do prédio dos Correios na cidade de Torres, RS.

Neste trabalho, foi utilizado num primeiro momento o método da pesquisa bibliográfica, para conhecimento do tema e da legislação pertinente. Além da NBR 9.050/2004, constituíram-se em importante base para este artigo os trabalhos de GOULART, 2006, DISCHINGER et. al. (2009 e 2012) e BINS ELY et. al. (2002), bem como a Cartilha de Acessibilidade Arquitetônica e Urbanística - Município legal é município acessível, do Ministério Público-RS (FERNANDES, 2010), o caderno do CREA-PR: Acessibilidade: Responsabilidade Profissional. (MESQUITA, 2011).

Após o aporte teórico, foram efetuadas visitas para conhecimento do local e de seu funcionamento, com o método Walktrough (WHARTON et. al., 1994), que consiste no reconhecimento do local em companhia de um funcionário, procedimento indispensável à compreensão dos trabalhos ali executados e dos serviços oferecidos à população. Não havendo plantas disponíveis, foram efetuadas medições do terreno e da edificação para a execução dos desenhos em 2D e 3D necessários ao trabalho.

A seguir o prédio foi avaliado através do preenchimento das Planilhas de Avaliação de Acessibilidade do Ministério Público de Santa Catarina (DISCHINGER et. al., 2012). Tais planilhas, resultantes de um trabalho em parceria com o grupo de pesquisa "Espaço Inclusivo: Núcleo de estudos em Desenho Universal" do programa Pós-Arq da UFSC, foram também avaliadas, resultando o presente trabalho também em sugestões de melhoria em seu conteúdo e aplicação. Por sua configuração a partir de questões em formato check list, relacionadas com os quatro Componentes de Acessibilidade, a aplicação das Planilhas MP-SC resultou em uma avaliação inicial já bastante ampla dos quesitos necessários à adaptação do prédio no sentido de torná-lo acessível, de acordo com a legislação vigente. 


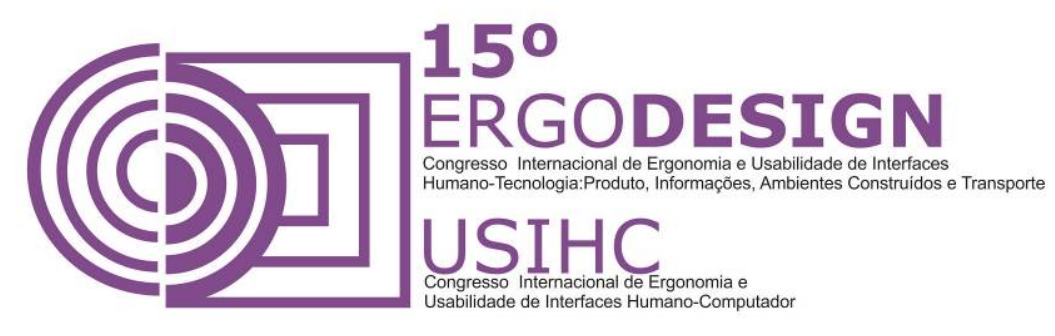

O método de Passeios Acompanhados (DISCHINGER, 2000) foi então realizado com uma cadeirante e um cego, através de roteiro e questões pré-estabelecidas. Tal método trouxe à luz outras questões importantes, não vislumbradas anteriormente.

A partir das etapas anteriores, foi efetuada a avaliação final, sendo então lançadas as propostas de adaptação dos ambientes interno e externo no sentido de tornar a edificação adaptada às exigências legais e acessível aos diversos segmentos de pessoas com deficiências. Por fim, foram feitas sugestões de inclusão de novos itens na Planilha 1 - ÁREAS DE ACESSO AO EDIFÍCIO e de acréscimo na Planilha 6 - LOCAIS PARA ATIVIDADES COLETIVAS, com a inclusão do subtítulo Refeitório.

\section{DESENVOLVIMENTO}

A cidade de Torres localiza-se no litoral norte do estado do Rio Grande do Sul, junto ao estado de Santa Catarina, conforme figura 1. Banhada pelo Rio Mampituba, divisa entre os dois estados, a cidade constitui-se num ponto turístico e num polo moveleiro importante, tendo apresentado nos últimos anos, um alto crescimento no setor da construção civil.

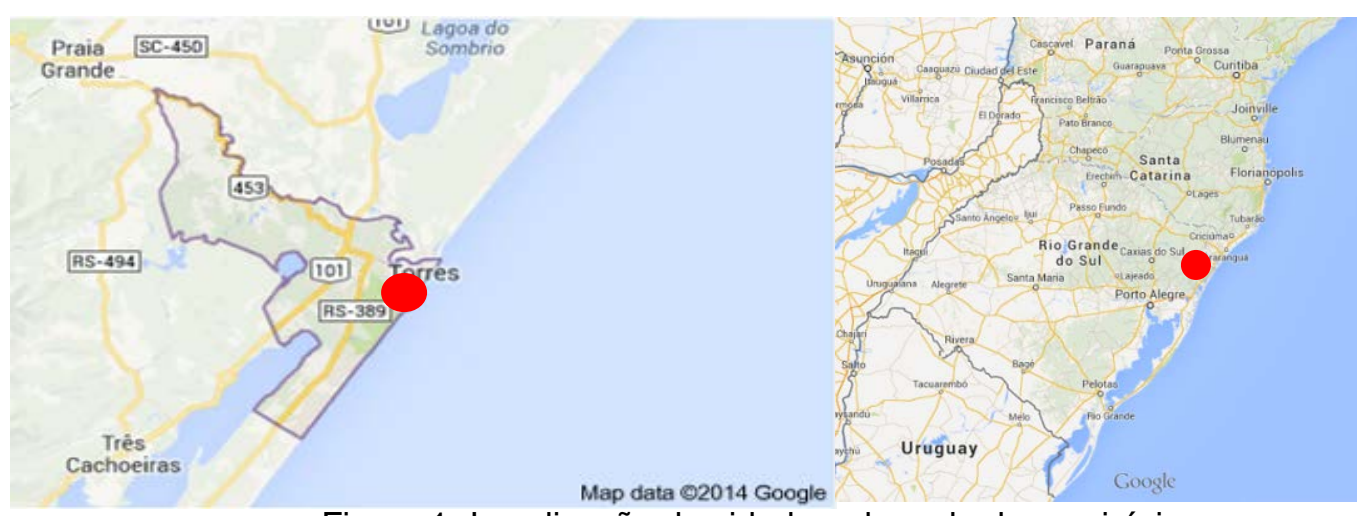

Figura 1- Localização da cidade e da sede do município

Fonte: Google Maps

O prédio dos Correios localiza-se na região central da cidade, junto à avenida principal e a bancos, lojas, bares, restaurantes e cafés (figura 2). Local de trânsito intenso no verão, passagem para uma das praias mais movimentadas e para diversos pontos turísticos, o local pode ser considerado o coração da cidade. O edifício de dois andares, construído na década de1970 (figura 3), localiza-se na Praça XV de Novembro (figura 4). 


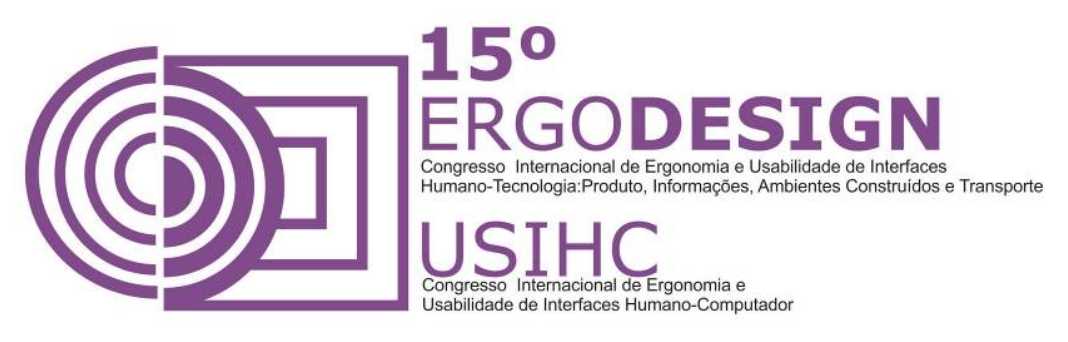

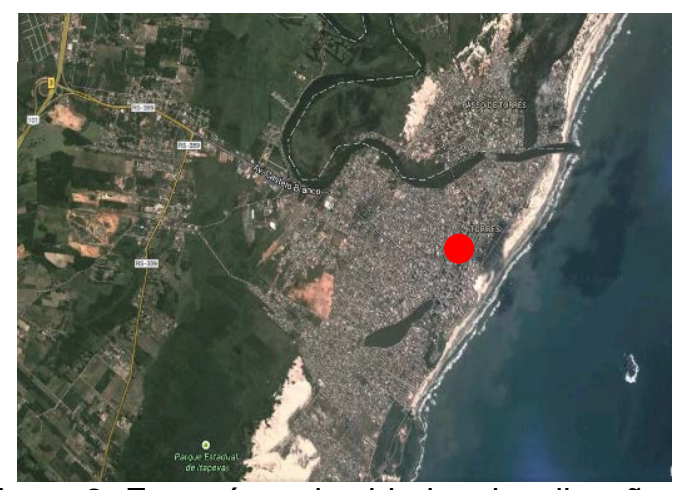

Figura 2- Foto aérea da cidade e localização do prédio dos Correios

Fonte: Google Maps

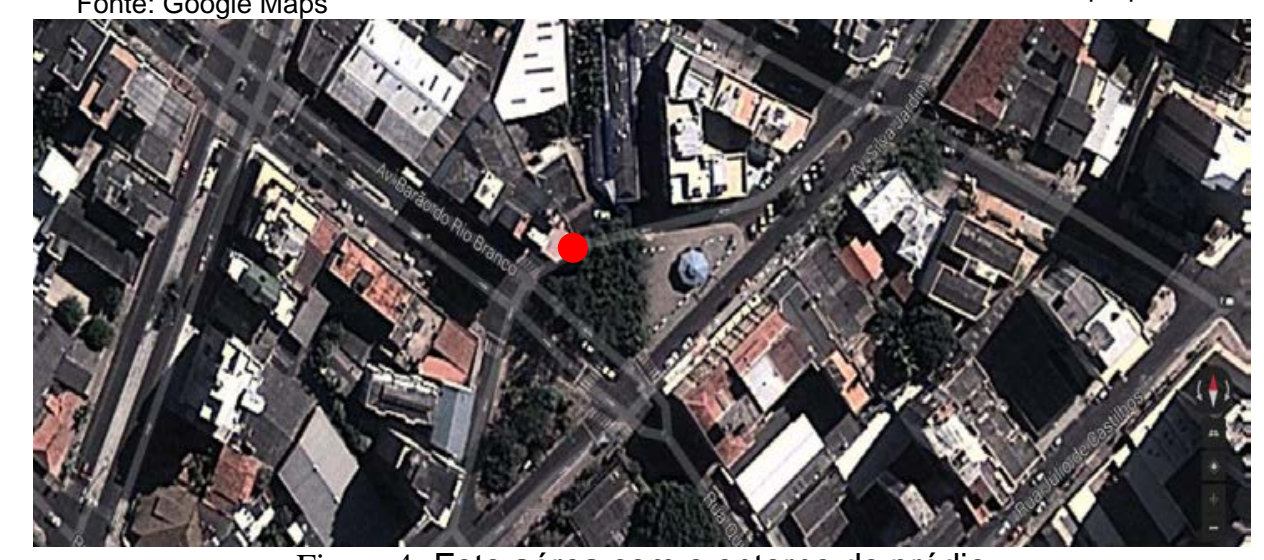

Figura 4- Foto aérea com o entorno do prédio Fonte: Google Maps

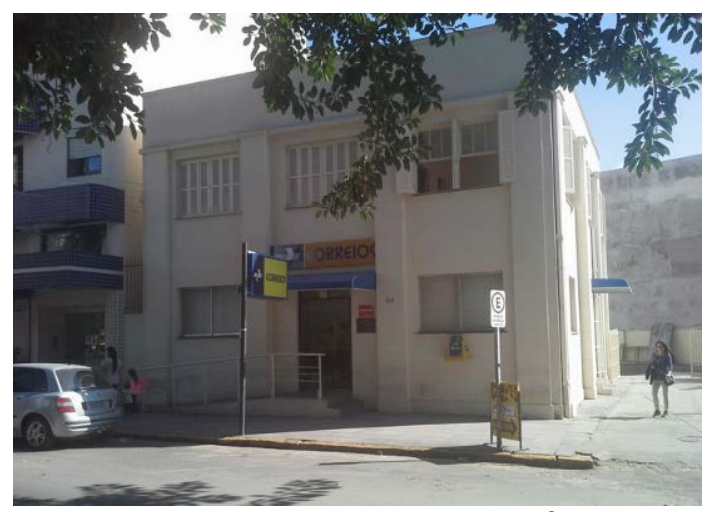

Figura 3- Foto externa do prédio Foto: autoria própria

\subsection{Aplicação dos métodos}

\subsubsection{Walktrough, levantamento e desenhos}

Situado a meia quadra da Avenida principal da cidade e com frente para duas ruas importantes, o lote irregular faz divisa a sudoeste com um alto edifício e a norte com um prédio de três andares. Os dois pavimentos da edificação são ocupados pelo órgão, mas apenas o térreo, em sua parte frontal, é destinado ao atendimento do público. Possui rampa e escada no acesso principal, ainda que não totalmente de acordo com a NBR 9.050/04.

O acesso ao pavimento superior onde funciona o refeitório dos funcionários, dá-se através de escada e o prédio não possui elevadores. Tampouco possui sanitários adaptados e não há empregados com qualquer tipo de deficiência. Os fundos do terreno abrigam um depósito e o pátio de carga e descarga, sendo que o acesso de veículos é feito pela via principal, paralelamente ao prédio, e não pela via lateral, o que representaria um trajeto mais curto e mais seguro, como pode ser constatado na figura 5. 


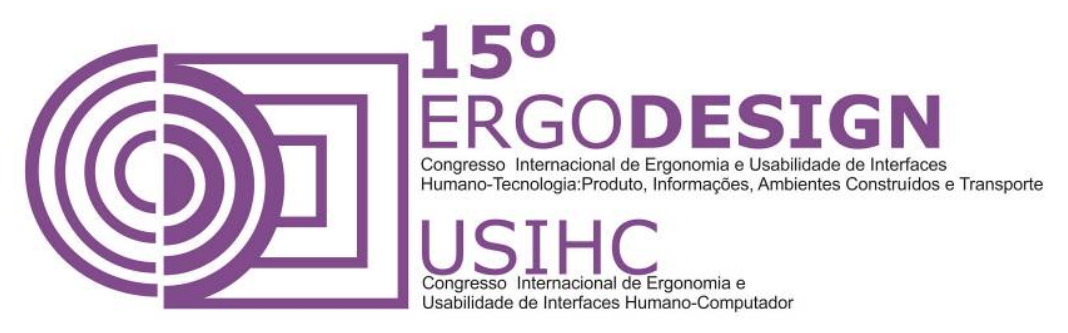

Internamente, o pavimento térreo divide o espaço destinado ao público entre o salão de atendimento e a gerência. No setor reservado aos serviços internos estão localizados os guichês de atendimento, a administração, os sanitários, a expedição, o depósito e o acesso ao segundo pavimento. Voltada à rua lateral, existe uma saída alternativa à principal, com muito pouco uso, enquanto uma terceira, apenas para serviços, liga-se diretamente ao pátio de carga e descarga (fig. 6).

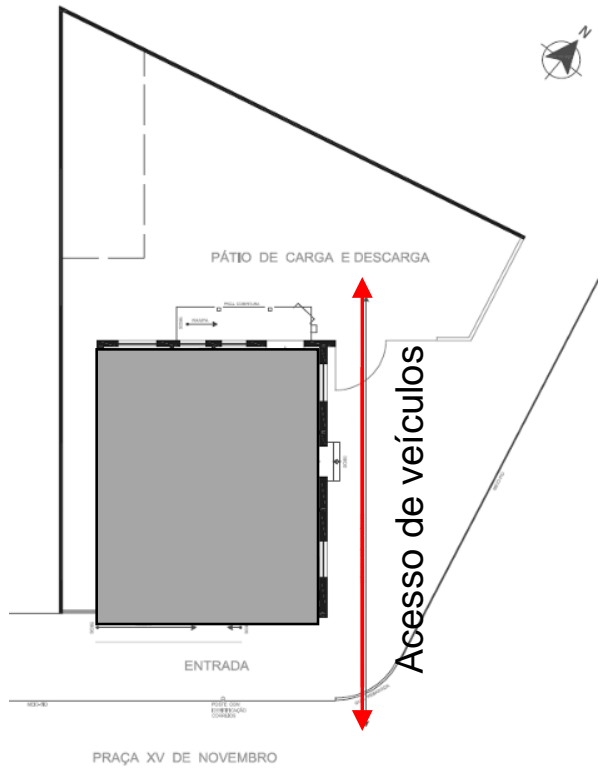

Figura 5- Terreno e Implantação prédio. Fonte: autoria própria

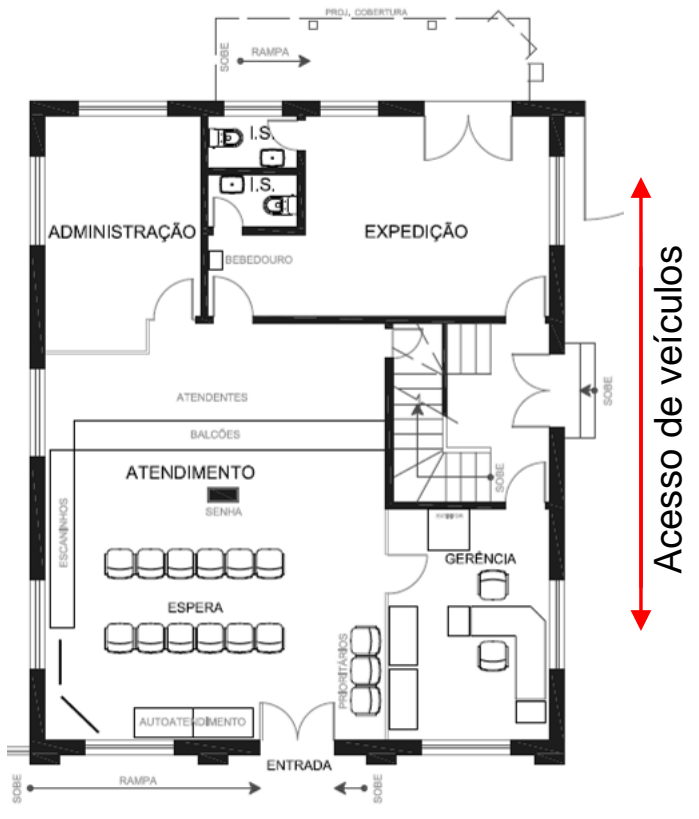

Figura 6- Planta Baixa Fonte: autoria própria

\subsubsection{Preenchimento das Planilhas MP-SC}

Foram preenchidas a seguir a Ficha de Identificação do Edifício Vistoriado (Figura 7), bem como as planilhas MP-SC aplicáveis aos caso, ou seja, a Planilha 1 - ÁREAS DE ACESSO AO EDIFÍcIO (em visão parcial na Fig. 8) e 2- SAGUÕES, SALAS DE RECEPÇÃO E ESPERA.

\begin{tabular}{|l|l|}
\hline Órgão: Correios & \\
\hline Nome do Edifício: & Edifício Próprio? $\quad$ Sim \\
\hline Ano de construção: Década de 1970 & O edifício é tombado? \\
\hline Endereço: Praça XV de Novembro, 24 Torres, RS \\
\hline Finalidade dos Serviços: Oferta de serviços postais e bancários \\
\hline$N^{\circ}$ de pavimentos do edifício: $\quad 2$ & $N^{\circ}$ pavimentos ocupados pelo órgão: 2 \\
\hline$N^{\circ}$ entradas: 3 & $N^{\circ}$ elevadores: $\quad 0$ \\
\hline$N^{\circ}$ rampas: $\quad 2$ & $N^{\circ}$ escadas: 4 \\
\hline$N^{\circ}$ apresentação/auditórios: $\quad 0$ & $N^{\circ}$ sanitários adaptados: 0 \\
\hline Vistoriadores: Arq. Carolina Jochims & Datas: 24/04/2014; 28/04/2014; 2/05/2014; 5/05/2014 \\
\hline$N^{\circ}$ visitas: 4 & \\
\hline Observações: & \\
\end{tabular}




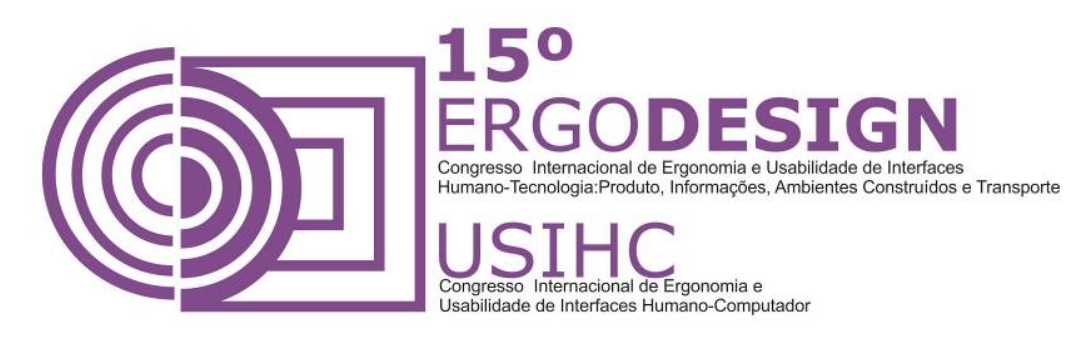

Figura 7- Aspecto da Ficha de identificação do Edifício vistoriado (DISCHINGER et. al. 2012)

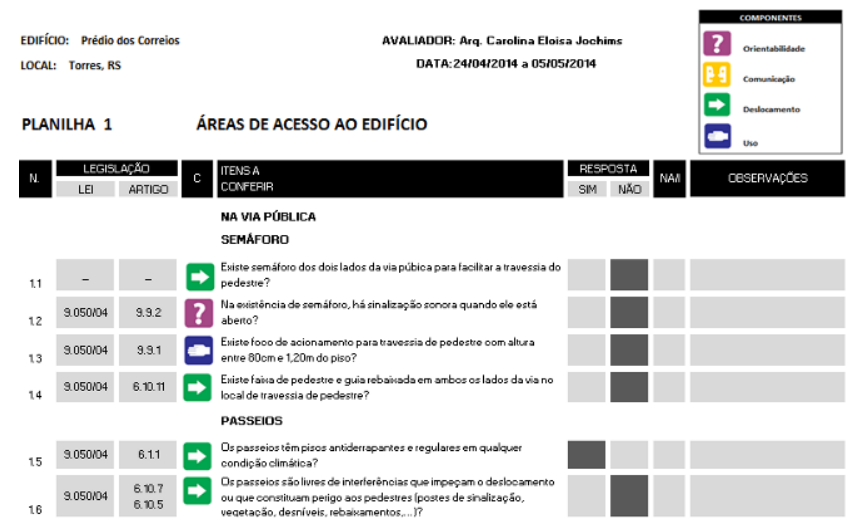

Figura 8- Aspecto parcial da Planilha 1 do MP-SC (DISCHINGER et. al. 2012)

\subsubsection{Análise inicial}

A partir da visualização do local, dos esclarecimentos de funcionário e da checagem através das planilhas MP-SC, a análise revelou que apenas três itens na edificação apresentam sinais de preocupação com a acessibilidade: a sinalização de identificação do prédio, tanto frontal quanto lateral; a rampa externa no acesso principal do prédio, ainda que com divergências em relação à NBR 9.050/2004; a área de espera na sala de atendimento, com espaço suficiente para cadeirantes. Além destes, algumas portas possuem a largura mínima legal.

Os demais quesitos, tais como alturas de mobiliários, larguras de passagens, trajetos livres de obstáculos, guias no piso, presença de sanitários acessíveis, alternativas de comunicação para surdos, sinalizações e configuração das saídas secundárias, entre outros, não possuem as características previstas pelas normas. Desta maneira, o prédio caracteriza-se como não acessível a deficientes motores, visuais e auditivos.

\subsubsection{Passeios acompanhados}
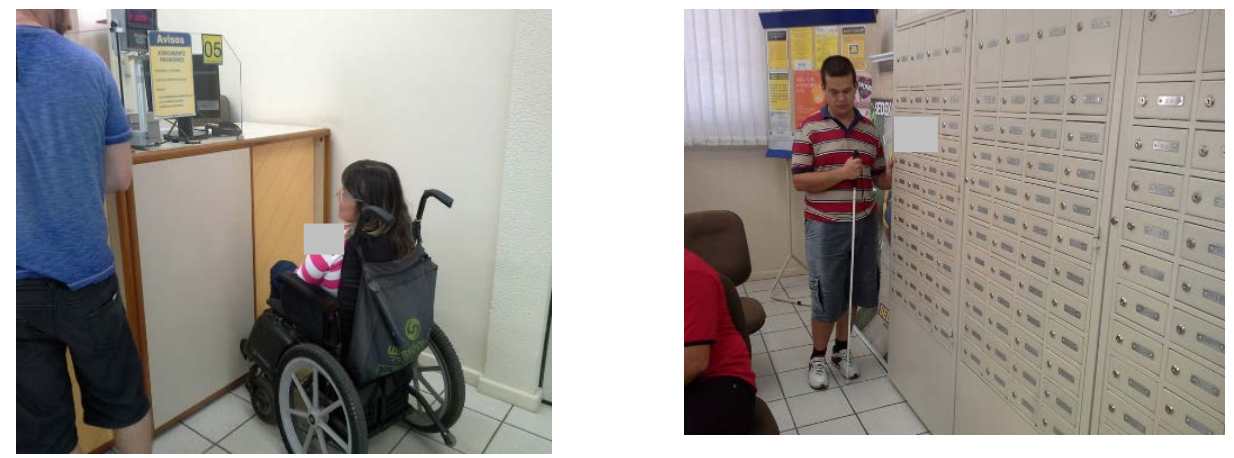


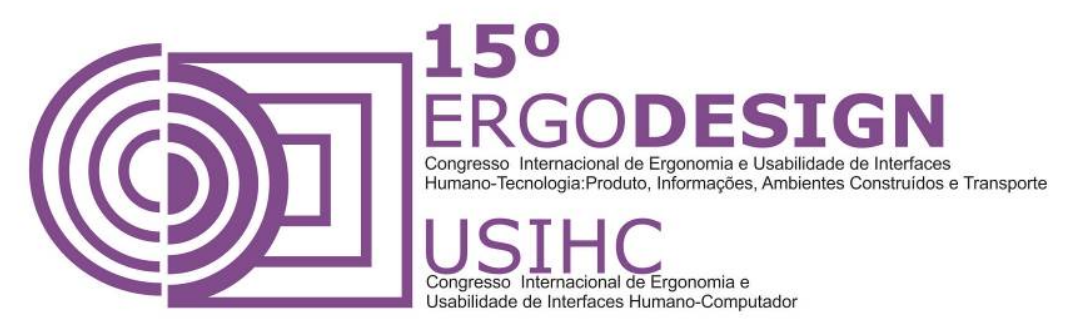

Figura 9 - Passeio acompanhado Cadeirante Foto: autoria própria

Figura 10- Passeio acompanhado Cego Foto: autoria própria

Os passeios acompanhados (DISCHINGER, 2000), realizados com uma cadeirante (Fig. 9) e um cego (Fig. 10), constaram de uma entrevista inicial informal na praça em frente ao prédio, seguidos de um trajeto interativo pelas instalações a analisar, com tarefas pré-estabelecidas e de uma entrevista final, nos mesmos moldes e local da inicial (figura 11).

As tarefas foram feitas sem a intervenção do avaliador, contando com sua orientação apenas em caso de necessidade. Os resultados dos dois passeios foram totalmente diversos, devido às diferentes condições de deficiência dos dois voluntários e, principalmente, devido às suas personalidades.

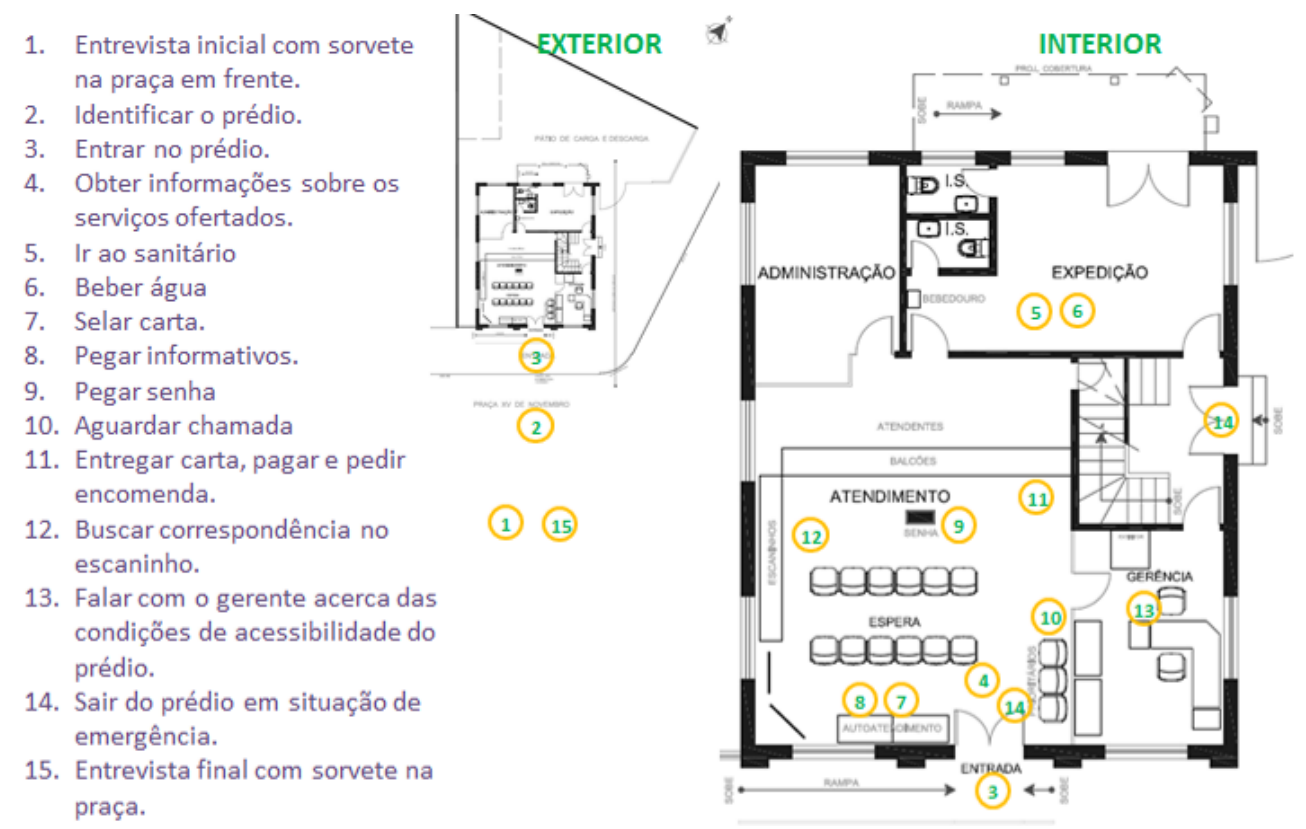

Figura 11- Roteiro dos passeios acompanhados Fotos: autoria própria

Luciane nasceu sem sustentação na coluna. Tem 45 anos, é artesã e fica em casa apenas quando está chovendo ou para fabricar suas peças, que vende ao público diretamente na rua. Faz fisioterapia e tem grande vitalidade, disposição e alegria de viver. As maiores dificuldades de Luciane em relação à deficiência são a falta de banheiros e de trajetos acessíveis. Como não há sanitários públicos acessíveis na cidade e tampouco em alguma loja, restaurante ou qualquer outro estabelecimento, cada vez que precisa ir ao banheiro tem de voltar para casa com sua cadeira de rodas, num trajeto de cerca de $3 \mathrm{~km}$. Não pode vender seu trabalho no Festival de Balonismo, festa anual importante na entrada da cidade porque não há caminhos 


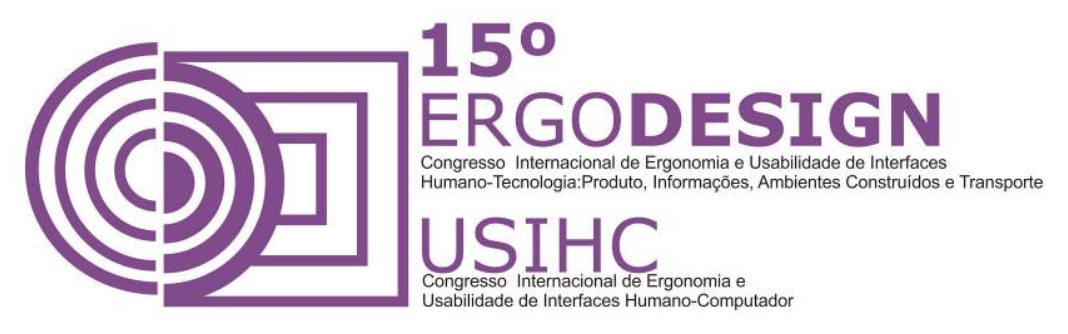

possíveis nem instalações acessíveis no local. Durante a visita, Luciane detectou muitas situações de inacessibilidade nas instalações do Correio, não percebidas antes, o que ajudou muito no processo de avaliação do local e de propostas de melhoria.

Leandro nasceu totalmente cego e tem atualmente 32 anos. É o mais novo da família e seu irmão mais velho, quase totalmente cego, formou-se em advocacia e trabalha na Caixa Econômica Federal. Leandro não estuda e quase não sai de casa, pois tem medo de tudo. Não domina a técnica da bengala, pois não precisa da mesma em casa. Toca violão, teclado e acordeão. De ouvido, é claro. Sua maior dificuldade com a deficiência são as calçadas. "Não dá para sair, pois dá medo de tudo". Durante o roteiro, suas manifestações foram: "Me ajuda!" "Estou com medo!" "Onde você está?"

$\mathrm{Na}$ entrevista final, Leandro declarou: "Não dá para fazer nada do que você pediu. Nem chegar lá sozinho". No entanto, quando foi levado para passear pela cidade, depois da visita, reconheceu a altitude do morro, o cheiro do mar, o barulho das ondas, a proximidade do rio e identificou marca e modelo do carro, apenas pelo som do motor. O voluntário não conseguiu fazer nenhuma das tarefas pré-estabelecidas, mas fora da visita, ensinou muito acerca dos sentidos que podem ser explorados para substituir a visão. Apesar de não utilizá-los de maneira plena, mesmo demonstrando ter capacidade para tal, foi revelador para a avaliação a importância dos sons, dos odores e da percepção do tempo e do espaço para os deficientes visuais. Revelador foi também o exemplo de quanto o medo pode ser incapacitador.

2.2.5 Avaliação final dos resultados e dos problemas encontrados nos ambientes interno e externo e propostas de solução

A partir da avaliação inicial, que já apontava diversos problemas, tais como obstáculos nas calçadas (Figura 12) e falta de caminhos acessíveis junto ao edifício (figura 13), foram incorporadas as questões levantadas pela aplicação do método dos Passeios acompanhados (DISCHINGER, 2000). Desta forma, foi possível efetuar uma avaliação final dos ambientes externos e internos do local, o que resultou em propostas de solução de problemas e de adaptação da edificação às questões legais.
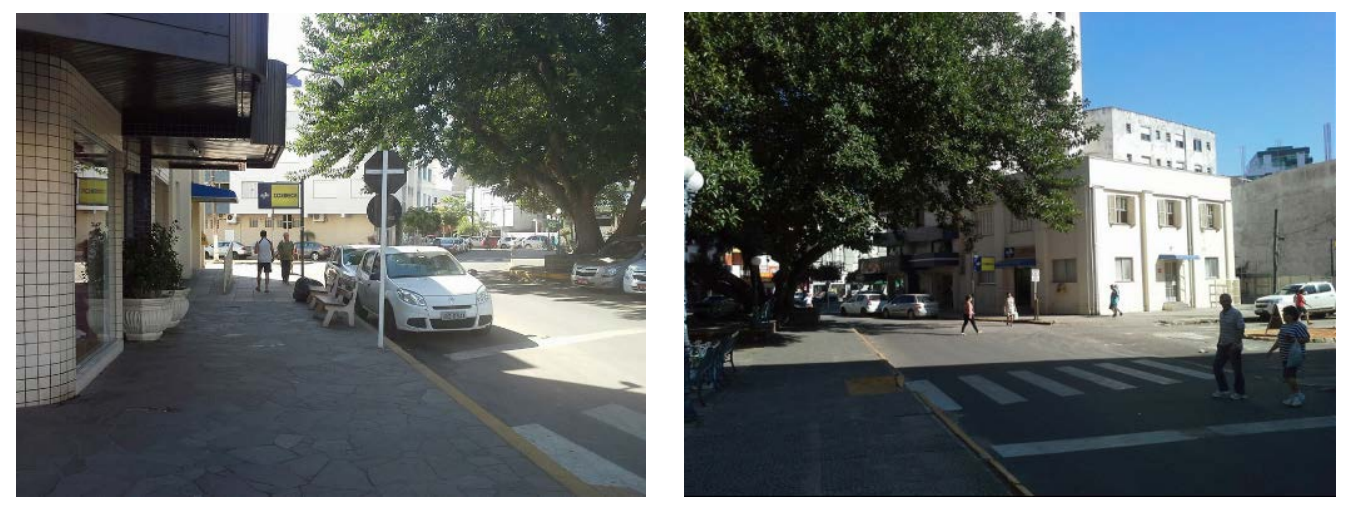


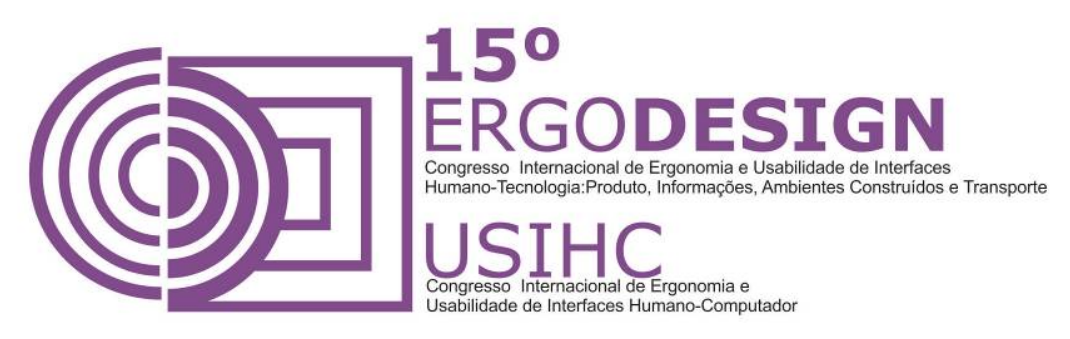

Figuras 12 e 13 - Entorno prédio dos Correios

Fotos: autoria própria

Dentre as propostas externas, destacam-se a implantação de caminhos acessíveis, do mapa tátil junto ao prédio e de áreas de estar junto às calçadas das duas vias, bem como uma realocação da entrada de veículos, devidamente sinalizada, para a rua lateral. Nos ambientes internos, além das questões de acessibilidade e sinalização, foi proposto, entre outros, o remanejo dos espaços, com a criação de um banheiro acessível, passível de uso público e a transformação da entrada lateral, de pouco uso, para uma saída de emergência alternativa, com rampa e escada acessíveis. Foram propostas ao todo, 34 intervenções, sendo 17 internas e 17 externas. As propostas foram demarcadas em plantas baixas e em perspectiva, conforme exemplos nas figuras 14, 15 e 17, sendo relacionadas aos respectivos componentes da acessibilidade (Orientabilidade, Comunicação, Deslocamento e Uso).

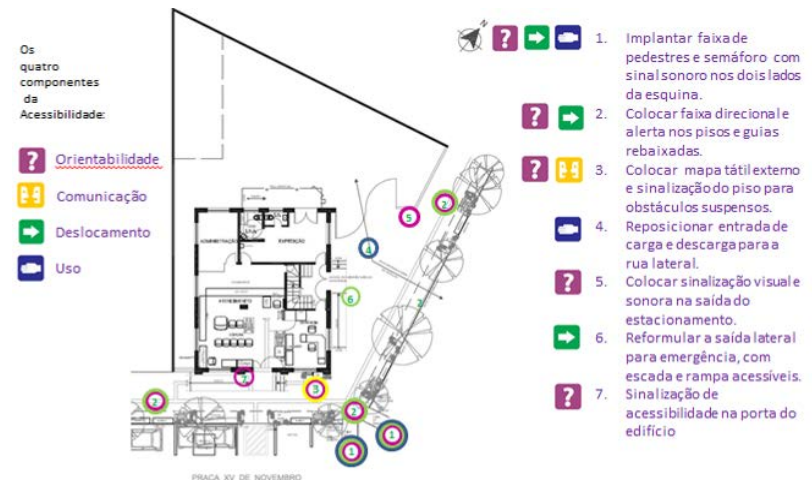

Figura 14- Desenho em 2D com as propostas de intervenção externas - I Fonte: autoria própria

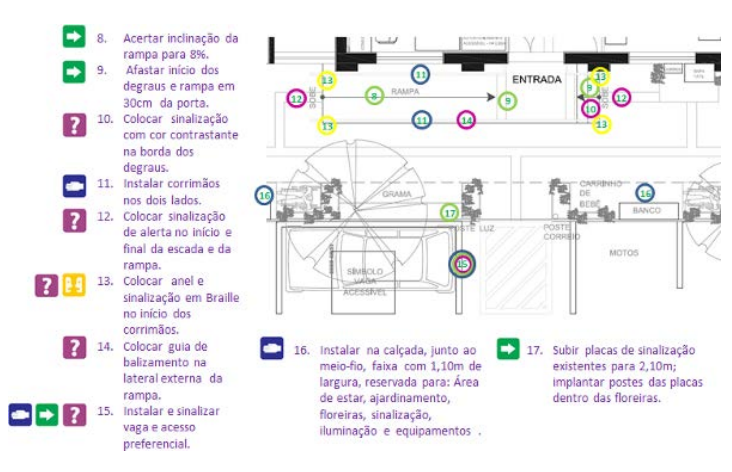

Figura 15-Desenho em 2D com as propostas de intervenção externas IIDetalhe do acesso principal Fonte: autoria própria

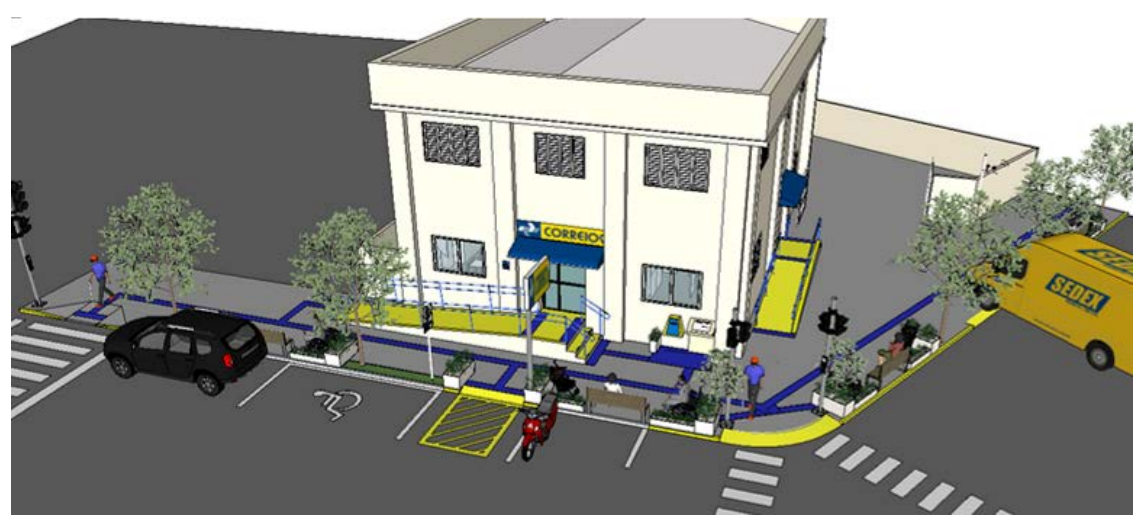

Figura 16- Desenho em 3D com vista geral do resultado das propostas de interveção externas 


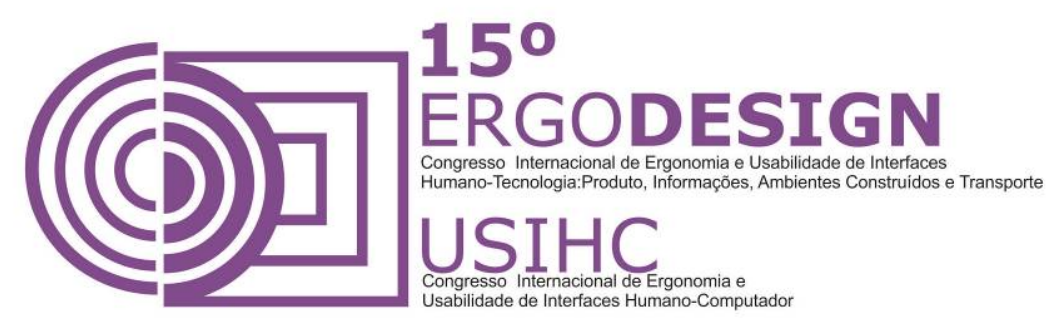

Fonte: autoria própria

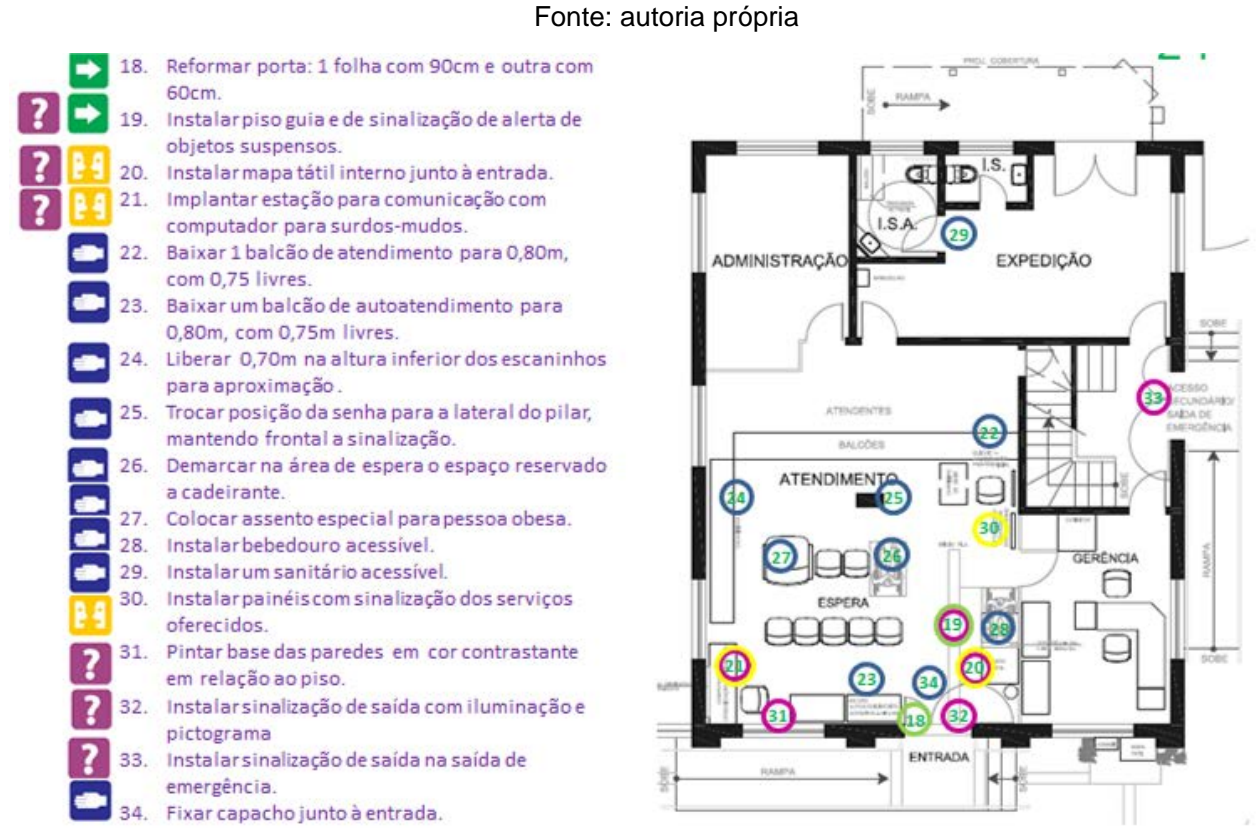

Figura 17- Desenho em 2D com as propostas de intervenção internas Fonte: autoria própria

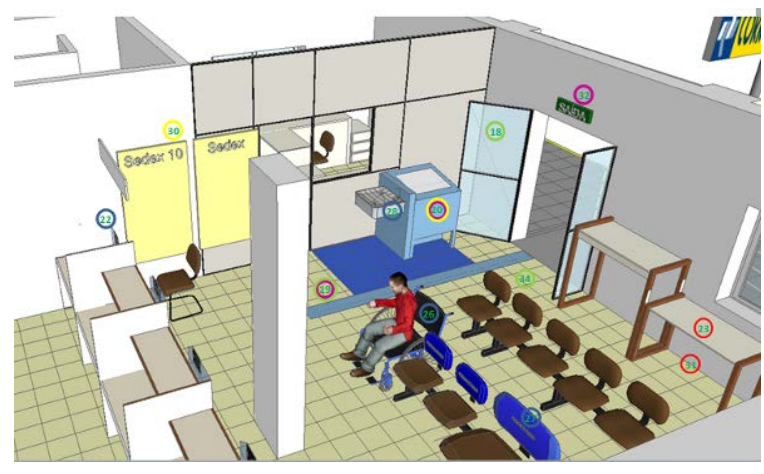

Figura 18- Desenho em 3D com vista geral do resultado das propostas de interveção internas I Fonte: autoria própria

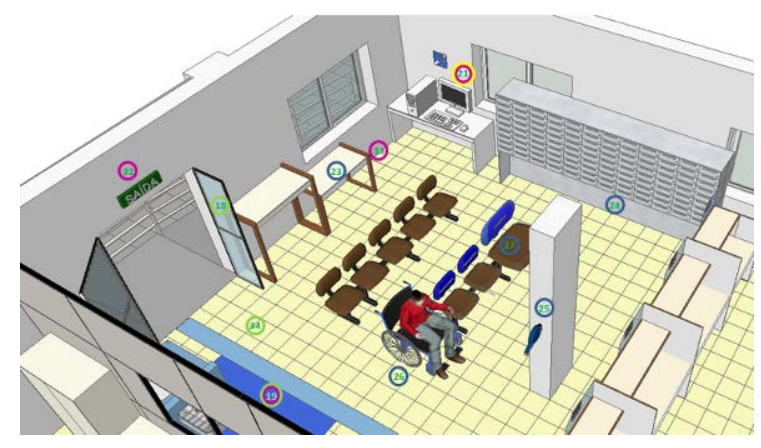

Figura 19- Desenho em 3D com vista geral do resultado das propostas de interveção internas II Fonte: autoria própria

A última etapa do trabalho constituiu-se em propor as alterações e acréscimos detectados durante o processo nas Planilhas MP-SC. Foram acrescentados novos itens na planilha 1 e criada uma nova secção na planilha 6. 


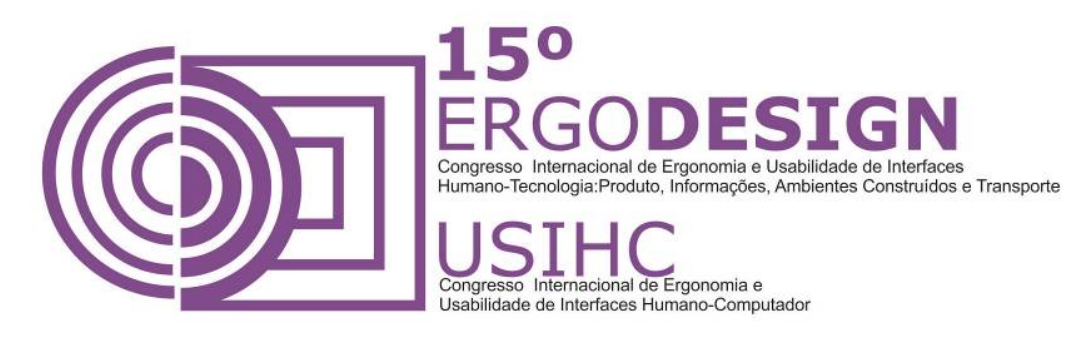

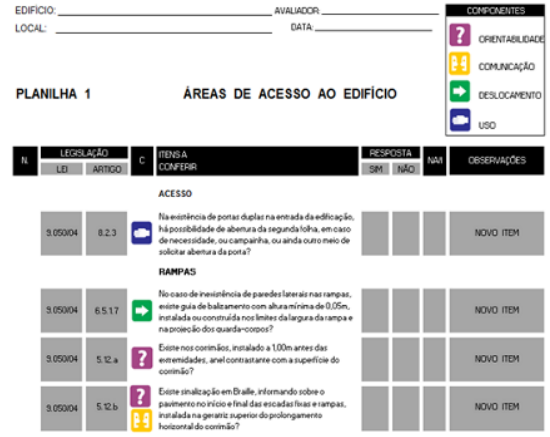

Figura 20- Novos itens propostos na Planilha 1 do MP-SC

Fonte: Autoria própria

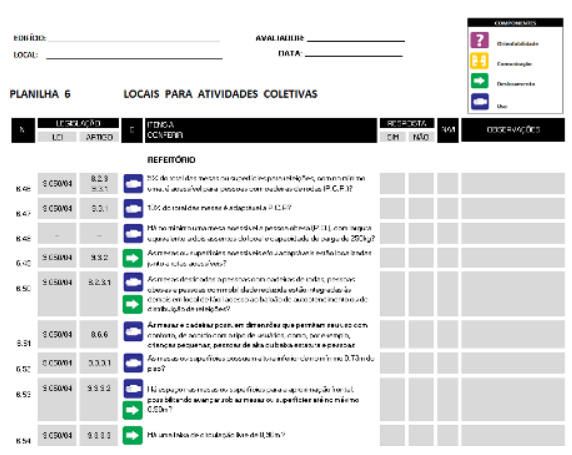

Figura 21- Vista parcial do subtítulo Restaurante proposto como acréscimo à Planilha 6

\section{CONCLUSÃO}

Fonte: Autoria própria

Os métodos utilizados, bem como a interação entre os mesmos, comprovaram ser de grande valor, tanto para a avaliação do local quanto para a execução das propostas de adaptação visando sua acessibilidade. As planilhas MP-SC (Dischinger et. al., 2012), com estilo check-list relacionados com os componentes da Acessibilidade foram de grande auxílio ao avaliador em relação à visão geral dos parâmetros, além de agilizar o processo de avaliação e possibilitar eventuais conferências, a qualquer tempo.

A interação entre o avaliador e os voluntários dos Passeios Acompanhados revela-se também muito importante, pois fornece, a quem não possui limitações, uma perspectiva por vezes inalcançável. A relação entre as intervenções propostas e os componentes da acessibilidade envolvidos nestas intervenções formou um dado bastante interessante, em que se destacam 0 componente orientabilidade nos espaços exteriores e uso no interior da edificação (Tabela 1).

Tabela 1- Relação Intervenções propostas x componentes da acessibilidade Fonte: Autoria própria
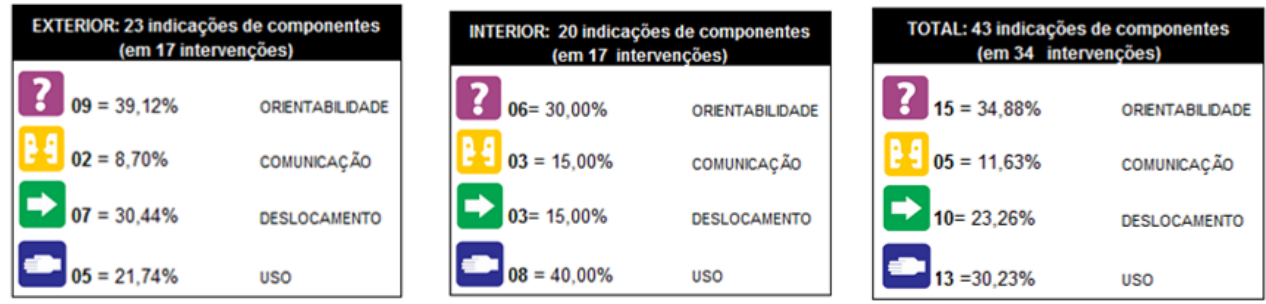

Esses dados refletem em grande parte o perfil dos voluntários dos passeios acompanhados e seria interessante uma análise dos resultados com pessoas portadoras de outros tipos de limitações, não decorrentes de deficiências, como por exemplo, de idade (crianças e idosos), mobilidade reduzida, mães com carrinhos de bebê, obesos e pessoas com estatura bem acima 


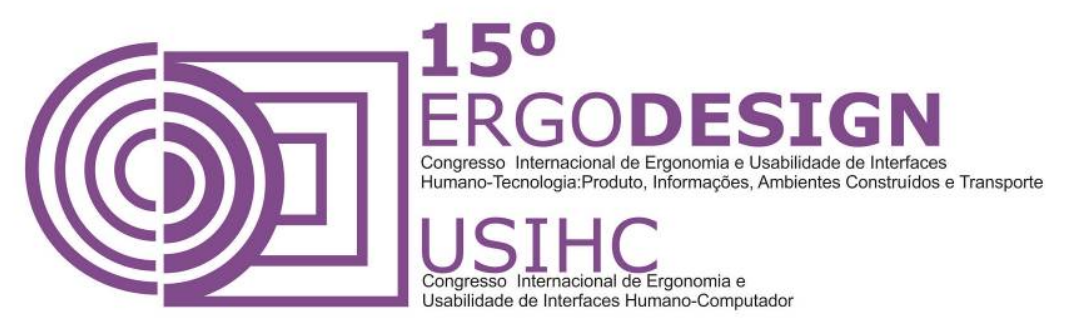

ou abaixo da média. Novas perspectivas de inacessibilidade seriam certamente acrescentadas.

As personalidades totalmente diferentes dos voluntários revelaram neste trabalho o quanto esse fator altera a condição final do deficiente. Enquanto a cadeirante revela-se mais pronta para enfrentar as dificuldades da vida, o cego se mostra limitado pelo medo. Apesar da perda da visão ser na prática bem mais difícil de superar, o exemplo do irmão do voluntário demonstra o poder da vontade e da coragem.

Finalmente, o resultado da avaliação do prédio e de seu entorno revelou claramente a ligação inseparável entre a acessibilidade das edificações e a acessibilidade da cidade. Prédios públicos acessíveis necessitam de entornos e de cidades acessíveis, pois, de outra maneira, como utilizá-los? Neste sentido, dos prédios públicos deveria se exigir não apenas 0 cumprimento às leis, mas um passo a mais: Que além de acessíveis, se transformassem em promotores da formação de "Ilhas de Acessibilidade", na medida em que prédios, praças e parques próximos se tornassem também acessíveis. Tais ilhas, como modelos de acessibilidade, poderiam inspirar então a criação de outras ilhas, que, interligadas entre si formariam cidades e pessoas mais humanitárias, mais conscientes, mais respeitosas e, antes de tudo, mais cumpridoras de seus deveres.

\section{REFERÊNCIAS BIBLIOGRÁFICAS}

ABNT. ASSOCIAÇÃO BRASILEIRA DE NORMAS TÉCNICAS. Acessibilidade de pessoas portadoras de deficiências a Edificações, Espaço. Mobiliário e Equipamentos Urbanos. NBR 9.050/2004. Rio de Janeiro: ABNT, 2004.

BINS ELY, Vera H.M.; DISCHINGER, Marta; DAUFENBACH, Karine; RAMOS, Juliana L. Contribuição de um método específico para a análise da relação entre o ambiente arquitetônico e a realização de atividades. ABERGO 2002.

DISCHINGER, Marta; BINS ELY, Vera Helena M.; PIARDI, Sonia M. D. G. Promovendo acessibilidade espacial nos edifícios públicos: Programa de Acessibilidade às Pessoas com Deficiência ou Mobilidade Reduzida nas Edificações de Uso Público. Florianópolis: MPSC, 2012.

DISCHINGER, Marta; BINS ELY, Vera H.M.; BORGES, Mona M.F.C. Manual de acessibilidade espacial para escolas: $O$ direito à escola acessível. Florianópolis: Ministério da Educação, Secretaria de Educação Especial, 2009.

GOULART, Vanessa. Acessibilidade para idosos em áreas públicas de lazer. Dissertação (mestrado). Universidade Federal de Santa Catarina. Programa de Pós-graduação em Urbanismo. 2006.

FERNANDES, Alexandre G. Cartilha de Acessibilidade Arquitetônica e Urbanística - Município legal é município acessível. Porto Alegre: MP-RS, 2010.

MESQUITA, Ricardo T. Acessibilidade: Responsabilidade Profissional. Cadernos do CREA-PR $n^{\circ} 4-$ Parte V. Série ética, responsabilidade, legislação, valorização e exercício das profissões da Engenharia, da Arquitetura e da Agronomia no Paraná. Curitiba: CREA, 2011. 